\title{
Simbólicas: vínculo femenino-cromático en Eguren
}

\section{Simbólicas: The female-chromatic bond in Eguren}

\author{
Susan Stephanie Llontop Gutiérrez ${ }^{1}$ \\ Universidad Nacional Mayor de San Marcos. Lima, Perú \\ susan.llontop@unmsm.edu.pe \\ ORCID 0000-0002-0848-3444
}

Citar como: Llontop, S. (2020). Simbólicas: vínculo femenino-cromático en Eguren. Desde el Sur, 12(1), pp. 23-35.

\section{RESUMEN}

En este artículo, nos hemos centrado en los poemas «Ananké», «Dama i», «Diosa ambarina», «La Walkyria» y «Syhna la blanca», del poemario Simbólicas, de José María Eguren, para determinar ciertas cualidades presentes en el universo femenino. La caracterización que se otorga a estos personajes femeninos está colmada de colores, con los cuales se describe su fuero interior y su exterior, así como también su entorno. De esta forma, la poética egureniana nos demuestra que el uso del símbolo sirve para evidenciar la insuficiencia de las palabras, del lenguaje, para transmitir un rasgo, una idea.

\section{PALABRAS CLAVE}

José María Eguren, Simbólicas, simbolismo, cromática, femenino

\section{ABSTRACT}

In this article, we focus on the poems "Ananké», «La dama i», «Diosa ambarina», «La Walkyria» and «Syhna la Blanca», from the collection Simbólicas, by José María Eguren, in order to discuss certain qualities that are present in the feminine universe. The characterization lent to

1 Bachiller en Literatura por la Universidad Nacional Mayor de San Marcos y tutora en la Universidad Peruana de Ciencias Aplicadas. Es miembro fundador de la revista de teoría y crítica literaria latinoamericana Heterogénea. Ha realizado una pasantía en Boston por el Program Student Leaders for the 21st Century. Además, ha sido ayudante de cátedra del curso Literatura Medieval. Su tema de interés es la literatura colonial del siglo XVIII. 
these female characters is filled with colors, through which their inner and outer selves are described, as well as their surroundings. In this way, the poetic aesthetic of Eguren teaches us that the use of symbols serves to demonstrate the inadequacy of words and language in the conveying of traits and ideas.

\section{KEYWORDS}

José María Eguren, Simbólicas, symbolism, chromatic, female

José María Eguren y el simbolismo, nacido a mediados del siglo XIX en Francia, usan la sugestión para demandar, ya sea en las palabras o en la imagen, la evocación misteriosa o multiforme: su naturaleza es el enigma mismo. En este movimiento hubo un evidente abandono de las fórmulas trilladas, la acogida de elementos raros y extraños dentro de la materia poética, sutileza y selección verbal, versolibrismo. No obstante, Eguren no solo toma los aspectos nuevos presentados en el simbolismo, sino que los combina con su propia concepción estética proveniente de su peculiar temperamento de artista. Estuardo Núñez $(1970$, p. 9) señaló que «Eguren se adelantó a su época, se apartó de los módulos tradicionales». Por otro lado, Mariátegui (1928, p. 253) expresa: «Eguren habría necesitado siempre evadirse de su época, de la realidad. El arte es una evasión cuando el artista no puede aceptar ni traducir la época y la realidad que le tocan». Su poesía supera al modernismo reinante y va en busca de un nuevo rumbo, con elementos frescos y ajenos a su época. A todo esto, sin embargo, los lectores incipientes no llegaron a comprenderlo, puesto que su poesía solicitaba una ardua tarea interpretativa. Como consecuencia, muchos tildaron a Eguren de pueril e infantil, pero todo esto ha de ser porque sus primeros versos estuvieron dirigidos a los integrantes más pequeños de su familia. De lo anterior, se puede rescatar la esencialidad espiritual en toda la poesía de Eguren. Mariátegui (1928, p. 246) la describe como «una versión encantada y alucinada de la vida». Parte de la poesía de Eguren parece emanar del subconsciente de un niño pequeño que por primera vez explora la naturaleza con toda su pureza.

Para empezar con los estudios sobre la cromaticidad en el poemario Simbólicas, publicado en 1911, se ha de saber que se iniciaron muchos años más tarde con las investigaciones de Estuardo Núñez, quien publicó en la revista Amauta un ensayo referido a la estética del color en la poesía de Eguren. En este ensayo se aborda la relación entre Eguren y los colores, y se explica que el poeta emplea sobre todo colores netos: azul, verde, rojo, amarillo. Asimismo, hace uso del color rojo para «objetivar elementos 
fantásticos», mientras que para «idealizar la materia y fantasear sobre el objeto» hace uso de los colores abstractos como el azul y el verde. Menciona, también, que en ningún momento Eguren emplea los colores como una simple característica natural, sino que los usa con un fin estético, es decir, provee de calidad poética al objeto al cual se le aplican. Como menciona Estuardo Núñez (1929, p. 32), «lo saca de donde lógicamente debe estar y lo lleva donde poéticamente quiere ponerlo», es decir, invierte los esquemas considerados como razonables con respecto a la utilización de tales colores en los objetos poéticos nombrados. Además, destaca el estilo poético y estético de la colocación del color, y lo contrasta con las ideas de Goethe en Teoría de los colores, publicado en 1810. Concluye en destacar el rasgo más original en Eguren: el colorismo poético, con el que Eguren se abastece para crear su mágico arte.

Más tarde, en 1932, el estudioso Estuardo Núñez desarrolla un ensayo más elaborado, basado, a su vez, en el breve ensayo aparecido en Amauta, titulado «La poesía de Eguren», donde toma las publicaciones de Eguren mayormente hechas de tipo ensayístico, reunidos bajo el nombre de Motivos, para extraer ideas del artista sobre el uso de colores. Además de centrarse en el análisis de los elementos, las técnicas y todo lo concerniente a la poesía de Eguren, Núñez señala que su poesía está repleta de significados intensos y compresos, es decir, que las palabras usadas cumplen una función estética en los versos egurenianos y dan a conocer un mundo de objetos, imágenes, música y colores expresados con elementos exclusivos. Sobre los colores en su poesía, Estuardo Núñez plantea a Eguren como un poeta de color así como lo es Chocano, solo que establece marcadas diferencias entre ellos. Al colocar la poesía de Chocano en paralelo con la de Eguren, observa que Chocano hace uso de colores que pueden resultar ser excitantes, brillantes, hirientes y chillones, mientras que Eguren solo usa aquellos que tienen unos tonos más apagados y pulcros, hacia una concepción estética suave y medida. Destaca el uso de colores netos como rojo, amarillo y azul, y evita el uso del matiz con pocas acepciones. Dicho en otras palabras, Eguren hace un juego de colores donde deja de lado lo trivial y común para dar paso a lo singular y novedoso.

Por otro lado, en 2004, aparece el artículo «El fuego y las presencias femeninas en la poesía de José María Eguren», en la revista Escritura y Pensamiento, escrito por Santiago López Maguiña, donde se reconoce la recurrencia del papel de las mujeres en la poesía de Eguren y las afilia al fuego y al calor, por lo que menciona que «la luz producida por el fuego está asociada con ellas» (López, 2004, p. 25). En base a esto, su estudio empieza por los análisis de estas presencias como seres atractivos, misteriosos $y$, sobre todo, luminosos. Y se menciona que son luminosos porque suelen 
portar algún rasgo que nos remita a la luminosidad o al fuego. Luego, López investiga la práctica de Eguren de mencionar «niña» en sus poemas, y concluye que no existe la certeza de que Eguren llame niñas a las niñas, es decir, objetivamente; sino que se puede interpretar en la palabra niña, una acepción al término mujer; dicho de otra forma, las niñas a las que se hace referencia puede que sean mujeres adultas, pero Eguren las llama niñas. Esta interpretación proviene de ver en estas presencias femeninas un espíritu vivaracho, travieso, juguetón y risueño, todo esto propio de las niñas, mas aparte de eso pueden ser eróticas y sensuales. Sus movimientos son de placer y goce, y sienten un deseo de compartir tiempo a solas lejos del resto con el amado. El estudioso López propone algunos ejemplos para aclarar su conjetura. Al inicio elige el poema «Nora». Nora es un personaje rodeado por figuras libidinosas y por esto puede ser identificada, más que con una niña, con una adolescente púber que despierta recién a la vida sexual. Luego, recurre al poema «Bella es Asia», donde el personaje femenino - luego de hacer una interpretación alegórica- parece presentar rasgos pertenecientes a los de una mujer madura y bastante pasional. Además, en «La niña de la lámpara azul», el ser femenino, la niña, intenta atraer o seducir con movimientos que conllevan fines sexuales, todo esto enmarcado en una intensidad luminosa presente en los términos usados en sus versos. Se sabe, también, que la luz tiene consigo una cualidad cálida que muchas veces es asociada con «los movimientos de atracción sexual». No obstante, si se refiere a la relación luz y fogosidad, López (2004, p. 33) señala lo siguiente: «Es una asociación muy extendida en la cultura occidental el amor, la pasión sexual se encierran y se inscriben perceptivamente en las sensaciones que proporcionan el fuego y el calor». Por otro lado, los ambientes presentados son exóticos, por lo que estimulan lo sensual y la fogosidad. López, de esta manera, determina que las presencias femeninas en la poesía de Eguren quedan dentro del marco del fuego, el calor y la luz, y que se relacionan con el movimiento fugaz, que puede interpretarse con amoríos o pasiones eróticas.

\section{«Ananké» y la naturaleza dual}

Este poema, que, según Estuardo Núñez, en Poesías completas y prosas selectas (1970), hace referencia a la diosa griega del Destino, nos remite a un pasado clásico; para ser más exactos, a la mitología griega. El análisis realizado del poema por Renato Guizado nos ayuda de gran modo a la comprensión de la relación que Eguren elabora entre el papel femenino y la cromática.

Al inicio de la interpretación de Guizado, se nos señala que la voz poética que le habla a la virtud —al nombrar el «labio purpurino»— la 
materializa al darle una característica corpórea. Más aún, no solo queda ahí, sino que también se sabe que el color púrpura es la suma del rojo con el azul y ambos tienen concepciones contrarias. En sus estudios de cromática, Estuardo Núñez señala que el rojo representa la vitalidad, la fuerza, lo corpóreo, mientras que el azul designa lo abstracto, lo fantástico y lo etéreo. De esta forma, juntos (el rojo y el azul) lograrían conformar un poderoso ser de naturaleza dual, como dice Guizado (2012, pp. 87-88), «material y espiritual, una característica inherente de la existencia». Es más, aquí reforzamos esa idea, se pueden tomar en cuenta las ideas desarrolladas en la obra Motivos (2005, p. 318) de Eguren, el motivo «Filosofía del objetivo», al inicio del cual menciona que «la Naturaleza es un cúmulo de fuerzas motoras, incesantes, su vitalidad es una harmonía, una compensación, un dualismo misterioso: alma y cuerpo, sujeto y objeto, vida y muerte; en estos principios la Naturaleza se postula y afirma». Entonces, volviendo al poema, la virtud, que es algo bello, motivo por lo que es bueno, adquiere una concepción en la que domina la dualidad equilibrada.

Además, el «labio purpurino», al que Estuardo Núñez (1970, p. 35) define como «de púrpura, rojo, de sangre», se puede asociar a la «queja» inicial del poema que denota sufrimiento por parte de la voz poética. Entonces, lo «purpurino» refuerza la hipótesis, ya que la sangre al secarse obtiene un color similar; de esta forma evoca dolor; este ser dual es algo o alguien que daña a la voz poética. Luego, la voz poética sigue hablándole a la segunda persona (que sigue siendo la virtud) y la vuelve a caracterizar a la virtud. Según Guizado (2012, p. 88), «el color azul produce la impresión de lo insondable, la inmensidad de la noche, sublime e infinita». Así, en el motivo «La Belleza», Eguren alude a que «toda belleza tiene un raro poder, causaría temor como todo lo que parece superar las leyes naturales, mas el temor pertenece a campo de lo sublime» (p. 282). He aquí que la virtud, que es bella, empieza ligeramente a tener una connotación negativa que sirve para que llegue a ser placentera. Sin duda, el aparente contraste creado entre «azul», refiriéndose a noche, y «matutina», más que colocarlos en oposición, los complementa para dar un efecto de vida, de símbolo de ciclo vital, que es anhelado. Sin embargo, después lo llama «goce fatal», pues por ser efímero como la vida es que resulta fatal.

Más adelante, la voz poética acusa a la virtud: «has pecado» pronuncia. La virtud peca por haberle infligido dolor, por lo que podemos llegar a que la voz poética busca transmitir o comunicar su dolor a la virtud. Aquí Guizado da cuenta de que este poema establece una relación de causa y consecuencia. Con todo esto, tenemos que la voz poética materializa a la virtud, «sin dejar de lado su parte abstracta» (p. 90); dicho por Guizado (2012), al otorgarle «labios» y «frente», en sí ya le está 
dotando de un rostro, motivo por el que se puede aseverar que esta virtud de naturaleza dual, abstracta y material, puede producir satisfacción como aflicción.

Finalizando con este poema, en la última estrofa es que recién la voz poética llama «niña» a este ser dual, y ella es el símbolo principal al que se refiere este poema. La niña no desea morir, puesto que Dios no la quiere por su condición de pecadora. Entonces, esto demuestra que puede seguir causando sufrimiento a la voz poética. Esta sugerencia de lo interminable o eterno es referida por no poder dar por finalizada la agonía del yo poético. La relación entre el título «Ananké» y los versos es temática, según los estudios de Guizado; las funciones de esta diosa griega van acorde con el destino y lo fatal, que de hecho son los temas centrales del poema. Nada sugiere sin lugar a reclamo que la niña del poema sea la diosa «Ananké»; sin embargo, la posibilidad de relacionarlas queda abierta.

\section{La condición natural en "La dama i»}

Este es uno de los más complejos a la hora de interpretar. Uno de los estudios en los que nos hemos basado, titulado «Eguren y la cifra del amanecer», proviene de Luis Fernando Chueca. Antes que nada, habrá de empezarse por la historia que nos narra el yo poético, la cual es de fácil percepción. Chueca (1999, p. 285) nos la resume de la siguiente forma: "Una dama, identificada como "i", inicia un recorrido en un lago y sobre una góndola de papel. En su ruta hacia una misa, canta - probablemente también danza-, recoge objetos y despierta sueños». Parece ser que su recorrido es rutinario, como una costumbre que se repite sin el mayor relieve; mas esa es su esencia, que la convierte en un hecho trascendente. Cuando la voz poética nos relata «Va en su góndola encantada, / de papel a la misa / verde de la mañana», el color verde nos evoca a la naturaleza, y no solo una palabra verde, sino lago, umbelas, aroma, hojas. «La geografía representada aparece asociada al tópico de la Naturaleza» (p. 288), menciona Chueca (1999). Entonces, tenemos que la palabra verde dicha por la voz poética es más bien referida al escenario por el que vaga la «dama i», un territorio pastoral. Podríamos establecer cierto vínculo entre la «dama i» y la naturaleza, en el que ambas se relacionan y la primera adquiere cualidades, como la belleza, de la segunda. En el motivo «La Belleza», Eguren menciona que «La Naturaleza es bella en cuanto es dinámica» (p. 282), por lo que la «dama i», al ser «vagarosa» y cantar mientras va por su ruta, y tener una cercanía con la naturaleza, adopta una belleza propia de la naturaleza.

Ya en la última estrofa se presenta: «Y parte dulce, adormida, / a la borrosa iglesia / de la luz amarilla». Según Estuardo Núñez, el color amarillo 
remite a lo trágico, así que se podría decir que la «dama i» reconoce esta «luz amarilla» en la «borrosa iglesia» en un estado de ensueño aún, no se sabe si medio inconsciente; lo que sí es que se dirige a ella «dulce» y «adormida», en un momento en el que no puede perjudicar a nadie $y$, sin embargo, es vulnerable hacia la realidad ignorada en aquella iglesia, y en el que su pureza es esplendorosa y pareciese que es lo único que puede defenderla. Para Chueca, el personaje principal es «una dama y en esta denominación observamos su pureza y consciente evasión de lo sexual buscada por Eguren en este poema» (p. 294). Los movimientos de la «dama i» son vagos y reflejan su libertad y su dinamismo; tal cual la naturaleza, sin una ubicación específica, está en todas partes y pertenece a todos.

\section{"Diosa ambarina" y lo exótico-misterioso}

Como podemos notar en el título del poema, esta diosa se identifica por ser relativa al ámbar, un color entre amarillo y anaranjado, que, según la concepción cromática egureniana, simboliza lo excepcional y extraño, lo exótico. Este poema nos ofrece, a modo de historia, una serie de hechos entrelazados. El yo poético menciona la llegada de los «vampiros blancos». Estos seres, que se caracterizan por ser misteriosos, enigmáticos y mágicos, de acuerdo con Estuardo Núñez y su estudio de los colores en la poesía de Eguren, van en busca de la hornacina de la diosa ambarina. No obstante, el yo poético menciona que se encaminan con sus «signos rojos». El rojo representa la intimidación y el miedo, por lo que se puede inferir que se dirigen con un sentimiento de amenaza hacia el altar de la diosa ambarina.

Luego, ya caída la noche, «dan al olvido, / ante la Tarde diosa», como sugiere Eguren en el motivo «El olvido de los recuerdos», «el recuerdo es una realidad, una vida, la vida repetida, pero este movimiento infinito se puede olvidar». Los vampiros blancos dan al olvido algo, es decir, lo que recordaban ahora ya no es más, se ha ido, y la contemplación de la Tarde diosa debe tener alguna conexión con la diosa ambarina, que es a quien ellos buscaban, porque la tarde es cuando ocurre el ocaso y el astro se oculta tras el horizonte, desplegando un color anaranjadizo, parecido al ámbar, para finalmente rezarle en un idioma propio al de ellos y desconocido por el resto, de la misma forma como en el motivo «La emoción del celaje» se menciona: «Un grupo de árboles sobre el celaje nos canta un idioma melodioso con palabras que no puede expresar» (p. 409).

Según Morales (2013, p. 63), «la Diosa ambarina del poema de Eguren está construida dentro de la estética del romanticismo negro, dentro del gusto por lo gótico». Gótico, por ser un personaje, en este caso una deidad, ambarina, cuyo color alude a lo macabro y que se identifica por estar 
ambientada en lugares misteriosos y desolados. De esta forma, Morales (2013, p. 66) afirma una cercanía entre Eguren y Westphalen, así como un distanciamiento, en Ha vuelto la diosa ambarina de este último, «quien ha regresado es la "diosa" de ámbar de Eguren», de la que Westphalen se vale para reafirmar su condición moderna; así es como evoca intertextualmente la imaginación «gótica» o la fantasía romántica negra, pero no la repite, sino le añade una reflexión estetológica.

\section{El mito nórdico de «La Walkyria»}

Empecemos primero con el estudio del título «La Walkyria», el cual nos refiere a la mitología nórdica, pues las valquirias eran vasallas de Odín. Estas divinidades femeninas se encargaban de abastecer su mesa de alimentos y, por otro lado, conforme a la orden de Odín, elegían quiénes debían morir en batalla y quiénes salir victoriosos. A eso se debe su nombre: val significa «muerte», por lo que ellas eran las encargadas de escoger a los muertos. En el mundo nórdico, el valor es lo único que puede opacar a la muerte, motivo por el que los héroes luchan con valentía sin temor a la llegada de la muerte, que ellos ven lejana. El poema «La Walkyria» inicia con la presencia en primera persona del yo poético, quien es a la vez personaje. Menciona quién es el yo poético: «la walkyria», no dice «Walkyria» ni «una walkyria»; de esta forma, busca reconocerse entre las demás y confirmar la existencia de ellas. Su ambiente son las arenas de batalla, y sin importar la vestimenta que presenten los jóvenes combatientes, la walkyria igual les hace llegar la muerte. Tampoco le importa el hecho de que los combatientes sigan una vida religiosa o fervorosa cuando señala «Ni vale tampoco la senda florida, / los cielos dorados, la luz de la vida». Usa la palabra dorado como variante del amarillo para sugerir una visión exótica de esa concepción religiosa.

Luego, continúa describiéndose a sí misma: «Soy flor venenosa de pétalo rubio / brotada en la orilla del negro Danubio». Con respecto a la amplia gama de sinónimos utilizados por Eguren, la palabra rubio es también una de las variantes del amarillo, que es usada para aludir a la muerte y a todo lo relativo a ella. Esta «flor» no nace en cualquier ambiente, sino en el oscuro y sombrío río Danubio que desemboca en el mar Negro, al cual Eguren caracteriza con la palabra negro. Así, nos manifiesta su origen ignoto en «mi origen no saben los cantos de gesta» y pone en relieve sus conocimientos sin dar mayor información de ellos. Continúa con la mención a los colores en: «Yo soy la que vuelvo contino las fojas / del mal: las azules, las blancas, las rojas». Sobre estos versos, señala Anchante (2012, p. 121) que estas «fojas del mal» $u$ hojas del mal presentan tres colores: 
Lo azul se puede asociar con el linaje de los guerreros o también con su edad núbil (el azul es característico de las jovencitas a las que se alude en muchos poemas); el blanco, con su origen o raza (nórdico y en general occidental como en el universo egureniano), o el momento previo a la guerra: la paz; el rojo, finalmente, como todo lo que atañe a violencia, sangre y muerte.

Más adelante, la walkyria hace referencia a una «ciencia maldita», sin nombrarla con exactitud, mas por el contexto del poema podemos imaginarnos que se trata de la astrología. Para finalizar, se asoma el saber en el poema «La Walkyria», pero no se lo puede obtener. Esto provoca una gran curiosidad que no se podrá satisfacer.

\section{"Syhna la blanca» y la violencia contra la mujer}

Este poema ha sido elogiado y comentado por Estuardo Núñez, Xavier Abril, César Debarbieri y Ricardo Silva-Santisteban. Nos apoyaremos en el comentario certero de este último para el análisis de este poema. La aparición de la cromática ocurre desde el título «Syhna la blanca». Coincidimos con Silva-Santisteban en pensar en que esta blancura hace referencia a la piel de Syhna o, si se lo toma simbólicamente, puede representar su pureza y su virginidad. Sin embargo, para Estuardo Núñez, el color blanco significa lo enigmático, lo mágico, y si tomamos estas reflexiones, podemos atribuirle a Syhna esta naturaleza fantástica, no real. Por lo pronto, se nos presenta la primera estrofa cargada de colores:

De sangre celeste

Syhna la blanca, sueña triste

en la torre de ámbar.

Por lo de la «sangre celeste», podemos inferir que su estirpe proviene de la realeza. Como sostiene Estuardo Núñez, «el celeste es de lo divino, por su relación con el cielo» (Anchante, 2012, p. 232). Después de mencionarse a Syhna la blanca y afirmar que «sueña triste», aparece el ambiente donde se halla, que es una torre de ámbar. Este color «ámbar» está en relación con el «blanco» inherente a ella; ambos evocan lo mágico, lo antiguo, lo exótico y misterioso. El hecho de que se encuentre en una torre, según Silva-Santisteban (2012, p. 179), conlleva un «significado ascensional o de elevación espiritual, una simbolización fálica».

En la siguiente estrofa se nos muestra a unos personajes preparando un «obscuro vino» a Syhna; no cabe duda de que sus intenciones no sean las mejores. Pronto, otros personajes hacen su aparición: «sueños» como personajes, y de ellos «azulean / la bruna laca». Azulear correspondería 
a volver todo más azul, y este color refleja lo abstracto, lo espiritual, una suerte de trascendencia más allá de la misma muerte. Este color funciona como verlo alterando a «bruna laca»; un barniz que debe cubrir alguna superficie de la estancia de Syhna es de color negro, es decir, remite a la oscuridad y a la muerte. Aquí, Silva-Santisteban presenta dos ideas, una es que «los sueños» pretendan cambiar de forma mágica el ambiente, y la otra es que se puede tratar de los síntomas que Syhna presenta por haber bebido la pócima que le prepararon anteriormente. Por nuestra parte, creemos que se trata más bien de la segunda propuesta. Syhna se encuentra en un estado en el que empieza a alucinar. Mientras, los «mudos rojos / cierran la ventana». Su objetivo es aprisionar a Syhna para evitar que escape y se presentan como «rojos» porque representan al color animal, a la violencia y a su producción de miedo.

En último lugar se encuentra la estrofa que hace referencia a lo inexplicable. Primero se nombra que «El cielo cunde», para luego señalar a «las elfas vagas», que son seres místicos nórdicos que siembran el terror en los jóvenes. Y cierra el poema con «y huye luego / la mansión cerrada». SilvaSantisteban propone el porqué de este desvanecimiento final de la imagen y de los hechos que ocurren en este ambiente en el que el yo poético es testigo: «La contemplación de sucesos horrorosos, para el espectador, cuya visión no puede soportarse» $(2012$, p. 186). Hemos decidido inerpretar este final como una suerte de fuga del lugar donde se ha producido (o se va a producir) una terrible acción. Es el ocultamiento de la evidencia, de los culpables y de la víctima, Syhna la blanca.

\section{Conclusiones}

La cromática de Eguren cumple un papel fundamental dentro de su poesía, pues permite que esta se transforme en algo más que en una transmisora de sentimientos, emociones o sensaciones, las cuales son comunicadas a través de los versos a los lectores. En estos poemas, la mujer, con toda la belleza con la que Eguren la representa, es identificada y caracterizada con una cromática amplia y variada, que unifica su personalidad y su ambiente, es decir, esclarece el poema a todas luces. Tal y como un pintor hace lo propio con sus cuadros, Eguren lo hace con sus poemas. Estos seres femeninos se presentan como verdaderas musas, personajes y protagonistas de sugerentes poemas. Aquella virtud que configura a estas presencias femeninas se halla enigmáticamente dentro de los versos. Eguren supo transformar un universo que albergara a estas mujeres tan diversas que representan seres duales, naturalezas, princesas, guerreras y hasta oscuros seres loados. 
Así como es representado su exterior, su belleza, lo es también el mundo interior de las mujeres representadas, establecido por la presencia de cromática, que refuerza estas virtudes y las integra para conformar un interior sólido y consistente, que cuente con características marcadas en el personaje y que propiamente concierne solo a los seres humanos reales. Eguren trata con estas presencias de forma delicada y respetuosa, si bien a veces las coloca en peligro $y$, al parecer, indefensas ante situaciones que escapan de su alcance — como en «Syhna la blanca»—, otras veces realza su cualidad exótica y misteriosa — como en «Diosa ambarina»—, así como también refleja la naturaleza dual, ser espíritu y cuerpo al mismo tiempo —como en «Ananké»-, recrea un mito nórdico con una figura femenina poseedora de secretos que no serán revelados a los demás - como en «La Walkyria»-, y, por último, conecta a la mujer con la natura, convirtiéndola en parte de ella o ella misma — como en «La dama i»- - Todas estas representaciones vienen acompañadas de una totalizante cromática, que es propia del placer estético egureniano.

Por lo tanto, se podría tomar como la poética de Eguren el ejercicio de utilizar constantemente los términos de color en las figuras femeninas para caracterizarlas, pues ellas son su objeto poético más anhelado. Sin embargo, solo se ha analizado y comentado cinco de estos poemas con esas particularidades, el amplio repertorio y la libertad desbordante del artista permitieron que pudiese usar esta técnica sugestiva propia del simbolismo. Los elementos que integran sus composiciones, entre ellos la cromática y la musicalidad, son valorados estéticamente por el poeta, quien es consciente de los tópicos que toca en sus poemas y que se desarrollan a lo largo de su trabajo poético, motivo por el cual decide hacer intervenir a la cromática, pero no de forma sutil, puesto que se pueden hallar colores funcionando, más que como adjetivos, como verbos, a la vista del lector.

Eguren ansía que los reconozcamos y que los vinculemos, ejercicio básicamente individual, con el contexto del poema de forma coherente. De esta forma, nosotros, como lectores, podemos ingresar al universo recreado con versos que manifiestan colores, donde existen mujeres bellas que son ideales con rasgos alterados por la fuerza del color que forma parte de cada una de ellas. La intención con la que el poeta vincula a los seres femeninos y a los colores queda despejada entonces; se vale de la fuerza de estos para que, al incluirlos en su poema, lo fortalezcan. Les da un énfasis mayor que al de cualquier ambiente, objeto o personaje dentro del poema. Es utilizar el símbolo para transmitir algún rasgo que no se puede representar en palabras humanas. En otras palabras, se evidencian los límites del lenguaje, del vocabulario. Por ello, Eguren emplea su gran 
abanico de colores que, como consecuencia, contribuye a que su poesía alcance su plena expresión artística.

\section{Contribución del autor}

Susan Stephanie Llontop Gutiérrez ha participado en la concepción, la recolección de datos, la redacción y la aprobación de la versión final del artículo.

\section{Fuente de financiamiento}

Autofinanciado.

\section{Conflictos de interés}

La autora declara no tener conflicto de interés. 


\section{REFERENCIAS BIBLIOGRÁFICAS}

Anchante Arias, J. (2011). Naturaleza y función de los símbolos en el poemario Simbólicas de José María Eguren (tesis de maestría). Pontificia Universidad Católica del Perú, Lima.

Chueca, L. F. (1999). Eguren y la cifra del amanecer. Aportes para la interpretación de «Dama i». Lienzo, 20, pp. 279-295.

Eguren, J. M. (1970). Poesías completas y prosas selectas. Lima: Universo.

Eguren, J. M. (2005). Obra poética. Motivos. Caracas: Fundación Biblioteca Ayacucho.

Eguren, J. M. (2012). Antología comentada. Lima: Academia Peruana de la Lengua.

López Maguiña, S. (2004). El fuego y las presencias femeninas en la poesía de José María Eguren. Escritura y Pensamiento, 15, pp. 25-36.

Mariátegui, J. C. (1928). Eguren. En Siete ensayos de interpretación de la realidad peruana (pp. 293-302). Lima: Amauta.

Morales Saravia, J. (2013). Mitigar avernos, padecer belleza: la poesía tardía de Emilio Adolfo Westphalen. Iberic@l, 3, 59-67.

Núñez, E. (1929). Ensayo sobre una estética del color en la poesía de Eguren. Amauta, 21, pp. 32-34.

Núñez, E. (1932). La poesía de Eguren. Lima: Ediciones Perú Actual. 